\title{
Air quality resolution for health impact assessment: influence of regional characteristics
}

\author{
T. M. Thompson ${ }^{1, *}$, R. K. Saari ${ }^{1,2}$, and N. E. Selin ${ }^{2,3}$ \\ ${ }^{1}$ Joint Program on the Science and Policy of Global Change, Massachusetts Institute of Technology, 77 Massachusetts, Ave., \\ Bldg E19-411, Cambridge, MA 02139, USA \\ ${ }^{2}$ Engineering Systems Division, Massachusetts Institute of Technology, 77 Massachusetts Ave., Cambridge, MA 02139, USA \\ ${ }^{3}$ Department of Earth, Atmospheric and Planetary Sciences, Massachusetts Institute of Technology, 77 Massachusetts Ave., \\ Cambridge, MA 02139, USA \\ *now at: Cooperative Institute for Research in the Atmosphere, Colorado State University, 1375 Campus Delivery, \\ Fort Collins, CO 80523, USA
}

Correspondence to: T. M. Thompson (tammy.thompson@ colostate.edu)

Received: 13 April 2013 - Published in Atmos. Chem. Phys. Discuss.: 30 May 2013

Revised: 22 November 2013 - Accepted: 8 December 2013 - Published: 28 January 2014

\begin{abstract}
We evaluate how regional characteristics of population and background pollution might impact the selection of optimal air quality model resolution when calculating the human health impacts of changes to air quality. Using an approach consistent with air quality policy evaluation, we use a regional chemical transport model (CAMx) and a health benefit mapping program (BenMAP) to calculate the human health impacts associated with changes in ozone and fine particulate matter resulting from an emission reduction scenario. We evaluate this same scenario at 36,12 and $4 \mathrm{~km}$ resolution for nine regions in the eastern US representing varied characteristics. We find that the human health benefits associated with changes in ozone concentrations are sensitive to resolution. This finding is especially strong in urban areas where we estimate that benefits calculated using coarse resolution results are on average two times greater than benefits calculated using finer scale results. In three urban areas we analyzed, results calculated using $36 \mathrm{~km}$ resolution modeling fell outside the uncertainty range of results calculated using finer scale modeling. In rural areas the influence of resolution is less pronounced with only an $8 \%$ increase in the estimated health impacts when using $36 \mathrm{~km}$ resolution over finer scales. In contrast, health benefits associated with changes in $\mathrm{PM}_{2.5}$ concentrations were not sensitive to resolution and did not follow a pattern based on any regional characteristics evaluated. The largest difference between the health impacts estimated using $36 \mathrm{~km}$ modeling results and either 12
\end{abstract}

or $4 \mathrm{~km}$ results was at most $\pm 10 \%$ in any region. Several regions showed increases in estimated benefits as resolution increased (opposite the impact seen with ozone modeling), while some regions showed decreases in estimated benefits as resolution increased. In both cases, the dominant contribution was from secondary PM. Additionally, we found that the health impacts calculated using several individual concentration-response functions varied by a larger amount than the impacts calculated using results modeled at different resolutions. Given that changes in $\mathrm{PM}_{2.5}$ dominate the human health impacts, and given the uncertainty associated with human health response to changes in air pollution, we conclude that, when estimating the human health benefits associated with decreases in ozone and $\mathrm{PM}_{2.5}$ together, the benefits calculated at $36 \mathrm{~km}$ resolution agree, within errors, with the benefits calculated using fine $(12 \mathrm{~km}$ or finer) resolution modeling when using the current methodology for assessing policy decisions.

\section{Introduction}

Air pollutants such as ground-level ozone and fine particulate matter (particulate matter with a diameter $<2.5 \mu \mathrm{m}, \mathrm{PM}_{2.5}$ ) have been found to impact human and ecosystem health negatively. To mitigate health damages, regulatory authorities have established maximum allowable concentrations of these 
pollutants. Because of the complex physical and chemical processes influencing both the formation and atmospheric transport of ozone and $\mathrm{PM}_{2.5}$, chemical transport models (CTMs) are used to inform regulatory strategies and to estimate health impacts of policies. CTMs aggregate processes spatially and temporally to evaluate the influence of chemistry, emissions and transport on concentrations. In atmospheric chemistry as well as a broad range of related scientific fields, the question of the selection of appropriate modeling scale is a challenge, and has become increasingly relevant as computational advances have enabled modeling at resolutions previously infeasible. Here, we apply a method elaborated previously (Thompson and Selin, 2012), with which it was shown that in policy-relevant applications such as air quality policy, the choice of model resolution requires consideration of the contributions of uncertainties associated with the policy, modeling and health impacts. We use this method to address the influence of varying meteorological patterns, current pollutant levels, and population densities, on determining the optimal resolution for regulatory air quality modeling of ozone and $\mathrm{PM}_{2.5}$ in the eastern United States.

Ozone and many of the species that make up the total concentration of fine particulate matter $\left(\mathrm{PM}_{2.5}\right.$ reported in this study includes particulate sulfate, nitrate, ammonium, black carbon and organic aerosols) are formed in the atmosphere from chemical reactions between precursor species. Often, these chemical reactions are non-linear, involve species from different sources and can occur at locations removed from where the precursor species were emitted. Strong spatial concentration gradients of emissions, as often seen near large point sources, can influence chemical production, and thus modeling at too coarse a resolution can lead to errors due to spatial averaging of emissions. As a result, many studies have found that models at coarser scale resolution $(>12 \mathrm{~km}$ grid cells) underpredict maximum concentrations, and overpredict minima (Arunachalam et al., 2006; Jang et al., 1995; De Meij et al., 2007; Tie et al., 2010). For ozone, this smoothing has been shown to reduce modeled ozone titration effects and ozone formation hot spots. Similar to ozone, studies suggest that regional air quality modeling results for PM concentrations improve with increasing resolution (Fountoukis et al., 2013; De Meij et al., 2007). However, many studies find that even $4 \mathrm{~km}$ resolution is not fine enough to represent the measured concentrations of PM accurately (Mensink et al., 2008; Ott et al., 2008; Shreshtha et al., 2009).

There are also challenges with attempting to model at too fine a resolution, as uncertainty is introduced into air quality modeling at almost every step of the process. Mensink et al. (2008) found that while local- and urban-scale modeling (resolution $<4 \mathrm{~km}$ ) provided more detailed data regarding PM exposure due to land use changes, these models were limited by their ability to account fully for the temporal patterns of secondary PM from sources outside of the region of study. Zhang et al. (2010) found that modeling future emission changes at both 4 and $12 \mathrm{~km}$ led to the same estimated percentage decrease in ozone at monitoring sites in North Carolina, but results for changes of total $\mathrm{PM}_{2.5}$ differed between the two resolutions (sometimes considerably: at 6 of the 37 sites they evaluated, the results had opposite signs). A related study (Liu et al., 2010) suggests that the higher sensitivity to model resolution of $\mathrm{PM}_{2.5}$ might be in large part to the challenges of meteorological modeling and geography. Queen and Zhang (2008) likewise found that increasing model resolution does not always improve the model's performance with respect to PM, suggesting that the highest sensitivity is to meteorological inputs, specifically rainfall. Fountoukis et al. (2013) found that finer resolution in both modeling and input emission inventories improved the performance of CTMs for primary PM species (most notably BC) and in some cases for secondary species. However, they also suggested that uncertainty in emission inputs might lead to larger discrepancies than model resolution between measured and modeled data.

In the United States, agencies require that air quality modeling for regulatory purposes be conducted at $12 \mathrm{~km}$ resolution or finer, and preferably at $4 \mathrm{~km}$ resolution (US EPA, 2007). Because attainment of US air quality standards is based only on concentrations at specific air quality monitoring sites, air quality modeling for regulatory purposes primarily focuses on reducing the model-estimated concentrations at those particular sites. In contrast, cost/benefit analysis of air quality policy, as required by Executive Order 12866 as it applies to the Clean Air Act (CAA), uses population-weighted concentrations of pollutants to estimate benefits. A recent analysis conducted to estimate impacts of the CAA addressed in a relative sense the potential impacts of many uncertainties introduced in the air quality modeling process. However, probability distributions were included only for concentration-response functions (US EPA, 2011a). Researchers have been called on to evaluate the many other sources of uncertainty in air quality modeling in order to aid in the policy decision making process (NRC, 2002). The complexity of regional air quality models and the computational and memory requirements, however, makes extensive uncertainty sampling approaches infeasible at $12 \mathrm{~km}$ resolution or finer at present.

While many studies as noted above have estimated the impact of model resolution on pollutant concentration, fewer have evaluated the impact of air quality model resolution on the estimated changes to human health. These few studies indicate that human health benefits estimated using fine model resolution $(<36 \mathrm{~km})$ do not provide more accurate results than human health benefits estimated using coarse model resolution $(\geq 36 \mathrm{~km})$ given the uncertainty associated with the human health response (Arunachalam et al., 2011; Thompson and Selin, 2012). These particular studies however are each limited in scope: the first to a single emission source (air travel) and only three regions (Atlanta, Chicago and Providence), the second to a single region (Houston). Thus, their general applicability to a broad range of meteorological 
conditions and background pollution/emission levels across the US is limited. A recent study of this type finds that a nationally averaged mortality estimation is $11 \%$ and $12 \%$ higher when modeled using $36 \mathrm{~km}$ resolution versus $12 \mathrm{~km}$ resolution for ozone and $\mathrm{PM}_{2.5}$ health impacts respectively (Punger and West, 2013).

We address the challenge of selecting appropriate model resolution for air quality benefit evaluation by applying a methodology that compares quantitative benefit estimation given model simulations conducted at varying resolutions (Thompson and Selin, 2012). Using an air quality policy episode for the entire eastern US, we conduct nested simulations of 36,12 and $4 \mathrm{~km}$ in nine regions of the US, evaluating the influence of urban versus rural land use, current attainment status (with respect to US National Standards) and coastal versus inland location on (1) the ability of coarsescale modeling to simulate changes in population-weighted concentrations of ozone and PM similarly to finer scale modeling, and (2) the errors contributed by model resolution changes relative to benefit evaluations. Section 2 presents the detailed modeling methods we use, including the air quality model (in Sect. 2.1) and the health benefit model (in Sect. 2.2). Section 3 presents the human health benefit results: first for ozone (Sect. 3.1) then $\mathrm{PM}_{2.5}$ (Sect. 3.2) and finally comparison of multiple concentration-response function results for a single illustrative region (Sect. 3.3). We discuss our results in Sect. 4 and compare the policy-relevant insights gained by modeling at these different resolutions in Sect. 5. We discuss implications of these findings to current regulatory procedures, human health benefit estimations, and the potential for model uncertainty analyses.

\section{Methods}

We follow regulatory procedures to first conduct air quality modeling using two emission scenarios, and then evaluate the human health impacts due to the differences between these emission scenarios at nine US locations representing a variety of regional characteristics. Repeating this analysis using three different model resolutions, we evaluate the impact of air quality model resolution on the resulting estimation of human health benefits across the selected locations.

\subsection{Comprehensive Air Quality Model with Extensions (CAMx)}

We use CAMx version 5.3 (www.camx.com), a regional air quality model that has been previously utilized by the US EPA and others for the purpose of regulatory decision making (TCEQ, 2009; US EPA, 2011b, 2012). We use a welldocumented year-long air quality episode developed and evaluated by the US EPA to evaluate the impact of the proposed Cross-State Air Pollution Rule - CSAPR (US EPA, 2011b). Emission inventories include a 2005 base case and a
2014 control case and were speciated and spatially and temporally processed using the SMOKE preprocessing system (CMAS, 2010). The 2005 base case inventory represents year 2005 emissions, while the 2014 emission inventories were first forecast from 2005 to 2014 by incorporating population and economic growth out to 2014, and incorporating all technological advancements available in 2010 and all air quality regulations passed by 2010 (when the forecast emission inventories were finalized); 2014 forecast emissions were then reduced by applying proposed controls on electricity generating units in the mid- and eastern US (US EPA, 2011c). On average, $\mathrm{NO}_{\mathrm{x}}$ emissions decrease by $35 \%$ from 2005 base case to control case, $\mathrm{SO}_{2}$ emissions by $56 \%$, $\mathrm{CO}$ emissions by $19 \%$ and volatile organic compound (VOC) emissions by $26 \%$ from the 2005 base year to the 2014 policy case. In contrast to methods in a traditional regulatory impact assessment, we compare the 2014 policy case to the 2005 base case rather than the 2014 projected base case, because the resulting ozone reductions from CSAPR are quite modest $(\sim 0.2 \%)$ and we prefer to explore a larger range to examine the non-linearities associated with ozone formation. The choice of policy case also encompasses a range of policy options covering emission sources with different characteristics. While the CSAPR targeted the electricity sector, EPA projects that additional policies and improvement in miles per gallon (mpg) reduce total emissions of $\mathrm{NO}_{\mathrm{x}}, \mathrm{SO}_{2}$ and VOCs from the on-road mobile sector by $45 \%, 85 \%$ and $45 \%$ respectively between 2005 and 2014 .

We explore three air quality model resolutions including a coarse parent grid at $36 \mathrm{~km}$ that covers the entire continental US, a nested $12 \mathrm{~km}$ grid covering the eastern US, and nine nested $4 \mathrm{~km}$ grids (Fig. 1) that are each $108 \mathrm{~km}$ by $144 \mathrm{~km}$ in size and are situated over areas of interest. CAMx output files are reported at an hourly time step. However, each process within CAMx is calculated at a time step that is internally determined by the CAMx model based on the spatial resolution (grid cell size) and on the process that is being calculated. As resolution increases, the internal model time step will decrease. The $36 \mathrm{~km}$ and $12 \mathrm{~km}$ model runs were conducted individually, using for our analysis only the model output from the grid cells falling within the nine selected regions. The $4 \mathrm{~km}$ results were obtained by running the nine regions as nine individual nested $4 \mathrm{~km}$ grids within the $12 \mathrm{~km}$ domain using two-way nesting. The areas chosen for this analysis were Atlanta, Boston, Washington DC, Detroit, Houston, New York State, New York City, western Pennsylvania, and Virginia. These sub-domains are selected to represent a variety of regional characteristics including population and industrial density, proximity to the coast, and existing attainment status. Figure 1 outlines the characteristics specific to each location. The results reported for each of the three resolutions come from these nine sub-domains only. Meteorological input files are the same for both the 2005 base case and the 2014 policy case (representing 2005 meteorological conditions) and were developed using the fifth generation Penn 
State/NCAR mesoscale model MM5 (Grell et al., 1994) for every day of 2005; for the $4 \mathrm{~km}$ domain, meteorological data are interpolated by CAMx from $12 \mathrm{~km}$.

The particular episode used for this study was selected because it represents recent federal efforts to improve US air quality via $\mathrm{NO}_{\mathrm{x}}$ and $\mathrm{SO}_{2}$ reductions under CSAPR and is therefore well-known within the regional modeling and health impact communities. Additionally, the episode performance has been evaluated (US EPA, 2011b). A detailed description of the episode including model evaluation is provided by the US EPA ( $2011 \mathrm{~b}$ - Appendix A). The $4 \mathrm{~km}$ domain was not included in the specific CSAPR modeling, but $4 \mathrm{~km}$ spatial surrogate files were created by the US EPA for the 2005 base case modeling episode using the same procedures used to create the 36 and $12 \mathrm{~km}$ spatial surrogates. We obtained those $4 \mathrm{~km}$ surrogate files from the US EPA in order to allocate the low-level area source emissions spatially to the $4 \mathrm{~km}$ grid with spatial detail that is improved over the $12 \mathrm{~km}$ domain. Emission totals are the same across all resolutions, and the spatial distribution, while showing increasing detail as resolution improves, is also the same (i.e., the emission totals in the $4 \mathrm{~km}$ grid boxes contained within each $12 \mathrm{~km}$ grid box sum to equal the emission totals of that $12 \mathrm{~km}$ grid box, and similarly from $12 \mathrm{~km}$ to $36 \mathrm{~km}$ grids).

As the $4 \mathrm{~km}$ domain was not included, it was also not evaluated within the cited EPA document, so a brief performance evaluation was conducted for this study by calculating mean normalized model error and bias (MNGE and MNB) with respect to daily maximum $8 \mathrm{~h}$ ozone and $24 \mathrm{~h}$ average $\mathrm{PM}_{2.5}$ (the two metrics input to health impact functions) at a single monitoring location within each domain. We found that modeled ozone MNGE and MNB decreased for the $4 \mathrm{~km}$ resolution versus both $12 \mathrm{~km}$ and $36 \mathrm{~km}$ in all regions except New York City where the $12 \mathrm{~km}$ domain results were superior. The model performance of $\mathrm{PM}_{2.5}$ was more varied with the $4 \mathrm{~km}, 12 \mathrm{~km}$ and $36 \mathrm{~km}$ resolutions each performing the best in three regions. More details of the model performance at $4 \mathrm{~km}$ resolution are provided in the Supplement Sect. S1 and Table S1.

\subsection{Health impacts}

For our analysis of health impacts and potential benefits, we use the US EPA's Benefits Mapping and Analysis Program (BenMAP) (Abt, 2010). Our health impact assessment methods (including BenMAP) closely follow those used by the US EPA for the Regulatory Impact Analysis (RIA) conducted to evaluate federal policy (US EPA, 2011d). Our inputs to BenMAP include modeled pollutant concentrations (daily maximum $8 \mathrm{~h}$ averaged ozone, and $24 \mathrm{~h}$ averaged total $\mathrm{PM}_{2.5}$ ), model domain grid definitions and projected 2014 census block population data (GeoLytics Inc., 2010) that is spatially allocated to $4 \mathrm{~km}$ grid cells using GIS software.

For each of the nine locations and three model resolutions, the inputs to BenMAP included: model grid cell domain def- initions, projected 2014 US population data, and pollutant concentrations for each day of the 2005 base case and the 2014 control case. These inputs are combined within BenMAP to estimate the change in average population-weighted pollutant concentrations between the base case and the control case. (Concentration changes presented herein are averaged for May through September in the case of ozone, and annually in the case of $\mathrm{PM}_{2.5}$.) The population-weighted concentration change serves as a best estimate of human exposure to air pollution and is applied to concentration-response functions and baseline health incidence rates (e.g., the baseline all-cause mortality rate) to estimate a change in mortality due to reduced pollution exposure. The modeled changes in population-weighted ozone and $\mathrm{PM}_{2.5}$ concentrations between the 2005 base case and the 2014 control case are reported and discussed in the Supplement. Where inconsistencies in population totals occurred due to rounding errors in grids in BenMAP (parent population data are based on census boundaries), we scaled the estimated mortality to the reported $4 \mathrm{~km}$ population so that population matched exactly.

We use a 2015 baseline mortality rate that is based on 2004-2006 individual-level mortality data (i.e., from records of individual deaths), as reported to the US Centers for Disease Control and Prevention (CDC, 2006), incorporated within BenMAP as county-level mortality rates and projected using national-level census mortality rate projections (Abt, 2010). These county-level mortality rates available within BenMAP were spatially allocated to the air quality grids at $4 \mathrm{~km}, 12 \mathrm{~km}$ and $36 \mathrm{~km}$ resolution, respectively.

The concentration-response functions applied in this study are those peer-reviewed epidemiological studies in BenMAP version 4.0 that estimate increased mortality risk. (The particular studies used are listed along the $x$ axis in Fig. 3a for ozone and Fig. 3b for $\mathrm{PM}_{2.5}$.) Daily maximum $8 \mathrm{~h}$ ozone (or $24 \mathrm{~h}$ averaged $\mathrm{PM}_{2.5}$ ) concentrations are input to BenMAP for the 2005 base case and the 2014 control case. The changes in concentrations are applied to a log-linear relationship between the changes in concentrations and increased mortalities, with no minimum health impact threshold assumed (US EPA, 2011e).

The uncertainties inherent in estimating mortalities from these functions are represented in this study in two ways. First, each epidemiological study has an associated $95 \%$ confidence interval (CI), which represents the statistical confidence of that study, given its methodology, population and sample period. Second, the differences in study designs themselves can give rise to non-overlapping confidence intervals when studies are compared. Users of BenMAP in regulatory assessments sometimes attempt to mitigate the latter source of uncertainty by appealing to expert elicitation (Abt, 2010) or using statistical techniques to develop representative impact functions (e.g., the PM NAAQS RIA (US EPA, 2012) or to pool estimates from multiple studies (e.g., the CSAPR RIA (US EPA, 2011d). Here, we do not pool the 


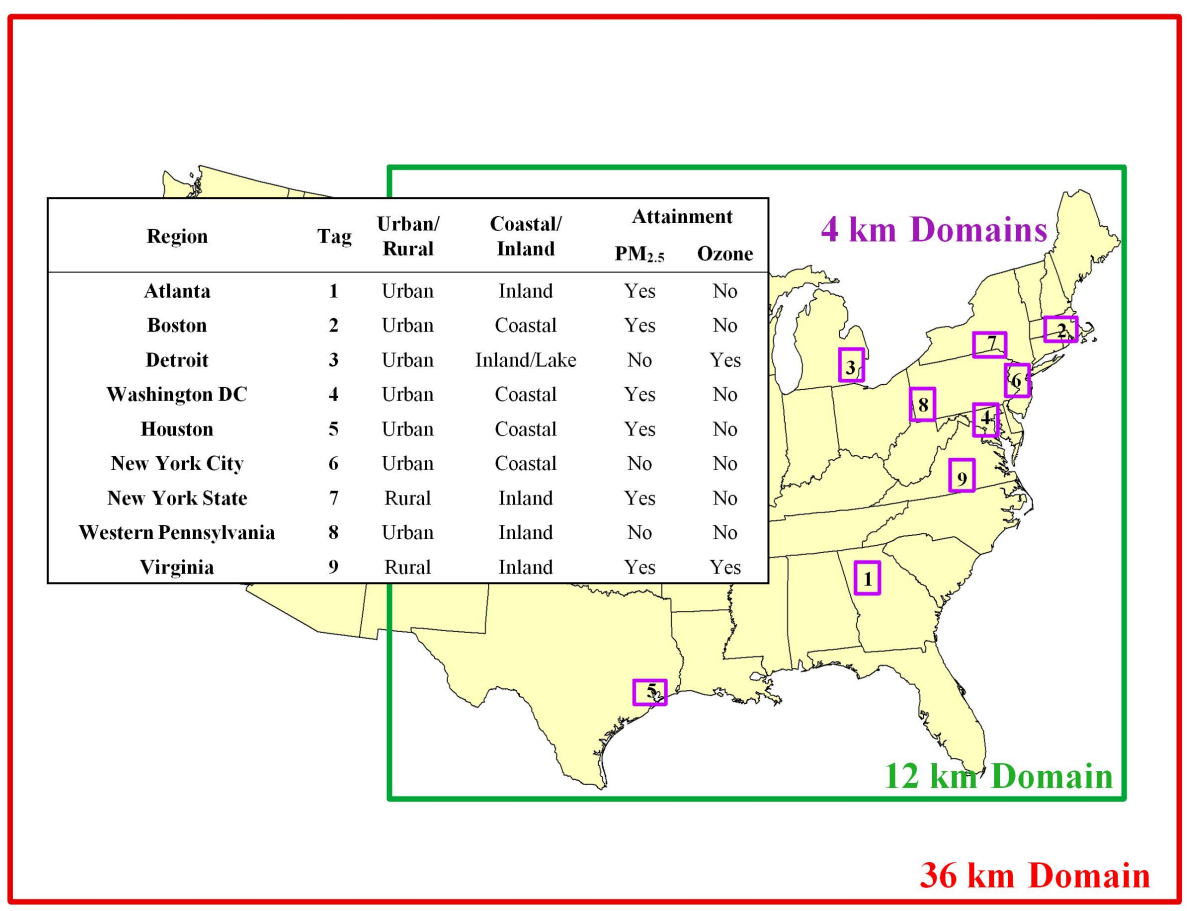

Fig. 1. Modeling domain: the extent of the $36 \mathrm{~km}$ domain is shown in red, the $12 \mathrm{~km}$ domain in green, and nine $4 \mathrm{~km}$ domains in purple. The results reported for each of the three resolutions apply to the nine $4 \mathrm{~km}$ sub-domains shown here.

health estimates. Instead we present all estimates for sideby-side comparison.

Throughout this study, we used the same population data (for year 2014), health incidence data (for the year 2015), and health impact functions in BenMAP. Native county-level population and incidence data in BenMAP were simply regridded within that program to our resolution of interest. From the discussion of local, fine-scale health impact assessment found in Hubbell et al. (2009), we chose to maintain consistent methodologies across our regions of interest so that our results could be compared across settings.

Mortality valuation determined using the value of a statistical life (VSL) typically dominates the monetized benefits associated with health improvements that come from mortality reduction (US EPA, 2011a); thus, we present mortalities exclusively.

\section{Uncertainty analysis of health impacts at varying model resolution}

Using BenMAP as described in Sect. 2.2, we calculate the estimated change in human mortality between the 2014 control case and the 2005 base case emission inventories for each of the nine regions of interest, and each of the three modeling resolutions. The point value of the estimated change in mortality is presented with a $95 \%$ confidence interval that represents the uncertainty associated with the concentration- response functions only. Apart from spatial resolution, other aspects of the air quality model uncertainty are not estimated.

\subsection{Impact of resolution on benefits associated with ozone}

Figure 2a shows the calculated decrease in mortalities due to changes in ozone between the 2005 base case and the 2014 control case (2005-2014), based on modeled populationweighted concentration data within each area, from the three different modeling resolutions applied to the mortality results from acute exposure estimated with Bell et al. (2004). For each endpoint (for both ozone and $\mathrm{PM}_{2.5}$ ), the mean value is marked by the red $(36 \mathrm{~km})$, green $(12 \mathrm{~km})$ and purple $(4 \mathrm{~km})$ slashes, and the $95 \%$ confidence interval is shown by the error bars. For ozone, in every sub-region studied regardless of population density, location, and current attainment status, the largest benefit due to the policy is estimated using the coarsest scale modeling $(36 \mathrm{~km})$. In three of the nine regions (Houston, Detroit and New York City), the $36 \mathrm{~km}$ point estimate for change in mortality falls outside of the $95 \%$ confidence interval for the two finer scale results. In Atlanta and Washington DC, the point estimate for the $36 \mathrm{~km}$ mortality results falls near the top end of the $95 \%$ confidence interval of the results calculated using the two finer scales. Maps showing the difference between 2014 and 2005 daily maximum $8 \mathrm{~h}$ ozone concentrations averaged for the ozone season over Atlanta, New York City and rural New York are 
presented in the top row of Supplement Figs. S1, 2 and 3 respectively.

\subsection{Impact of resolution on benefits associated with $\mathbf{P M}_{2.5}$}

Figure $2 \mathrm{~b}$ shows the estimated decreases in human mortality resulting from reductions in $\mathrm{PM}_{2.5}$ between the 2005 base case scenario and the 2014 control scenario calculated using the concentration-response function developed by Laden et al. (2006). The function developed by Laden et al. (2006) and used here estimates long-term effects from $\mathrm{PM}_{2.5}$. Unlike ozone, $\mathrm{PM}_{2.5}$ mortality results do not appear to be as sensitive to model resolution when uncertainties are considered. This is due in part to the mix of primary and secondary species that make up $\mathrm{PM}_{2.5}$. While primary $\mathrm{PM}_{2.5}$ species did show a trend of increasing impacts with increasing resolution, as supported by other findings (Fountoukis et al., 2013), secondary $\mathrm{PM}_{2.5}$ dominated the impacts and did not show a correlation to resolution. $\mathrm{PM}_{2.5}$ mortality decreases are on the order of 100 times greater than ozone mortality decreases. Maps showing the difference between 2014 and 2005 annual average $\mathrm{PM}_{2.5}$ concentrations over Atlanta, New York City and rural New York are presented in the bottom row of Supplement Figs. S1, 2 and 3 respectively.

\subsection{Impact of concentration-response function on estimated human health benefits}

Figure $3 \mathrm{a}$ and $\mathrm{b}$ below show the estimated avoided mortality calculated at each resolution, in the region surrounding Atlanta for all peer-reviewed concentration-response functions (CRFs) available within BenMAP version 4.0 for (a) ozone and (b) $\mathrm{PM}_{2.5}$. Atlanta results are presented here as an illustration. However results from all regions are presented in the Supplement and discussed below. As shown in Fig. 3a, three of the eight ozone CRFs show $36 \mathrm{~km}$ mean mortality estimates that fall outside of the $95 \%$ uncertainty range of the two finer resolution estimates. The avoided mortality due to the change in ozone concentration estimated using $36 \mathrm{~km}$ results is $40 \%$ larger than $4 \mathrm{~km}$ results on average for each of the CRFs. However, when comparing CRFs, the average difference between the largest and smallest mean values of different ozone CRFs calculated using results from the same resolution is $300 \%$. In contrast, the estimated avoided mortality due to changes in PM concentrations in Atlanta differs by only $7 \%$ between resolutions for each CRF, and the mean estimates differ by $150 \%$ between CRFs when keeping resolution constant. Estimated human mortality is thus more sensitive to the selection of concentration-response function than it is to the selection of air quality modeling resolution for both ozone and $\mathrm{PM}_{2.5}$.

\section{Discussion}

Estimated changes in mortality due to ozone concentration changes are sensitive not only to resolution but also regional characteristics. Changes in mortality due to total $\mathrm{PM}_{2.5}$ concentration changes are relatively insensitive to resolution or regional characteristics.

The results shown in Fig. 2a suggest that $36 \mathrm{~km}$ resolution modeling has the potential to overestimate ozone benefits in populated urban areas. Human health benefits were larger for ozone calculated at the $36 \mathrm{~km}$ resolution than at the $12 \mathrm{~km}$ or $4 \mathrm{~km}$ resolution for all nine regions evaluated. Most of the difference between resolutions in these regions occurs in urban areas. In urban areas, the human health response calculated at $36 \mathrm{~km}$ resolution is, on average, $200 \%$ larger than the response calculated at $12 \mathrm{~km}$ resolution, compared to $8 \%$ in rural areas. Houston and New York City have extreme differences between resolution results. Even excluding those two regions, the remaining urban areas showed a $50 \%$ greater ozone benefit at the $36 \mathrm{~km}$ resolution compared to $12 \mathrm{~km}$. In contrast, other regional characteristics considered did not seem as sensitive to resolution. Specifically, the impact of resolution did not seem as important when considering an area's current ozone attainment status or proximity to the coast. When considering local- and regionalscale impacts, it is important to keep these results in mind when interpreting human health benefits related to changes in ozone concentrations that are evaluated using coarse-scale or global-scale modeling.

Unlike the ozone results where coarse model resolution $(36 \mathrm{~km})$ leads to the largest concentration and thus estimated impact in mortality, $\mathrm{PM}_{2.5}$ concentration does not show a trend with respect to model resolution. In order to investigate the relative impacts of primary and secondary $\mathrm{PM}_{2.5}$ on total $\mathrm{PM}_{2.5}$, we evaluated the human health impacts of primary and secondary $\mathrm{PM}_{2.5}$ individually by first calculating the change in modeled concentration (between 2005 and 2014) in total primary $\mathrm{PM}_{2.5}$ for three regions at each resolution (Atlanta, rural New York and New York City). We then calculated the change in modeled concentration of total secondary $\mathrm{PM}_{2.5}$ species in the same three regions. Finally, we applied these concentration changes to BenMAP independently, following the same methods outlined in this paper. We found that secondary $\mathrm{PM}_{2.5}$ provides, on average, three times the total health impacts versus primary $\mathrm{PM}_{2.5}$. We also found that the magnitude of human health benefits of primary $\mathrm{PM}_{2.5}$ increase by about $22 \%$ between $36 \mathrm{~km}$ and $4 \mathrm{~km}$ resolution with $4 \mathrm{~km}$ resolution showing the greatest health benefit due to reductions in primary $\mathrm{PM}_{2.5}$. The magnitude of human health benefits associated with secondary $\mathrm{PM}_{2.5}$ varies by about $10 \%$ between the largest benefit and the smallest benefit. However, there is no correlation between the largest benefit and model resolution (i.e., in Atlanta, the largest benefit due to secondary $\mathrm{PM}_{2.5}$ was estimated using a $36 \mathrm{~km}$ resolution, while in both New York regions it was 


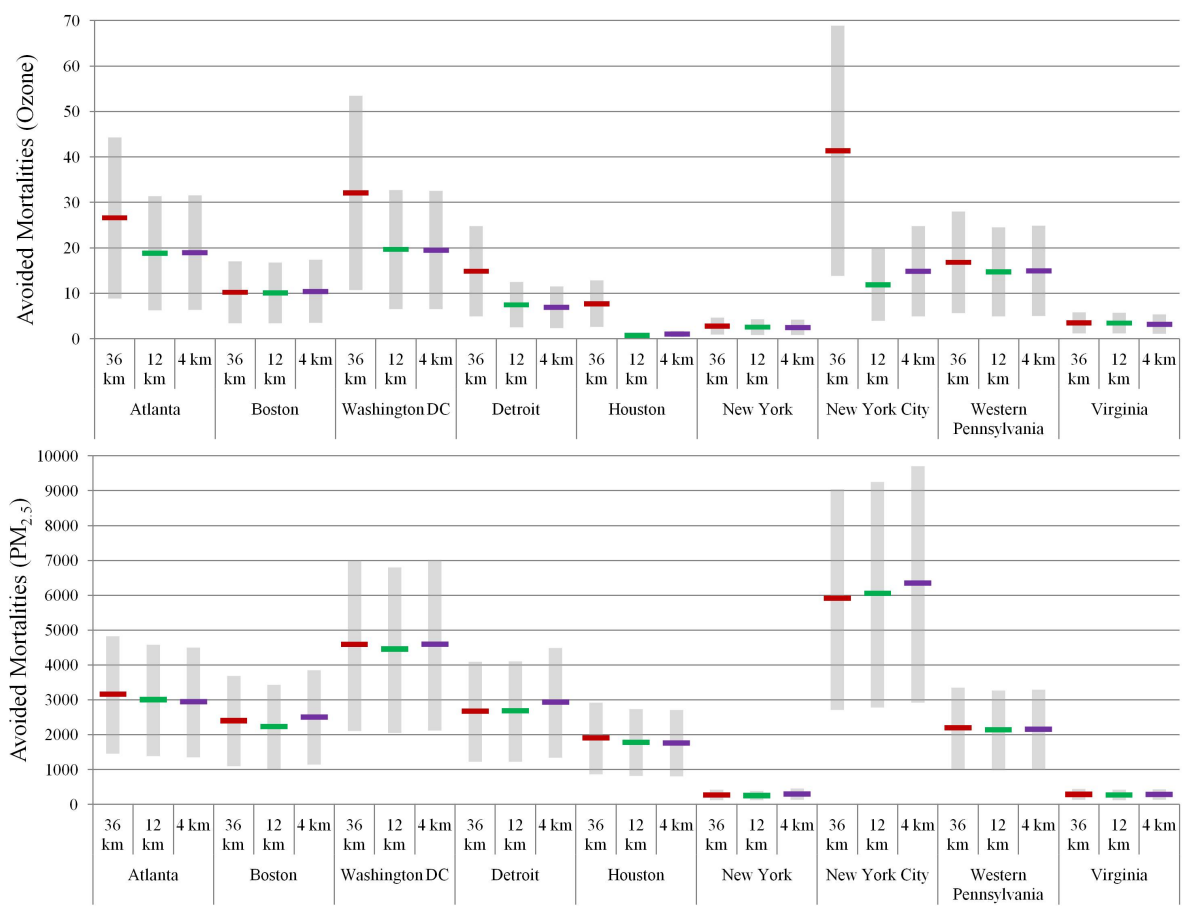

Fig. 2. (a) Mortalities avoided due to changes in ozone concentrations between the 2005 base case and the 2014 control case for each model resolution (red indicates $36 \mathrm{~km}$, green $12 \mathrm{~km}$, blue $4 \mathrm{~km}$ ), calculated using the concentration-response function developed by Bell et al. (2004). (b) Mortalities avoided due to changes in $\mathrm{PM}_{2.5}$ concentrations between the 2005 base case and the 2014 control case for each model resolution (red indicates $36 \mathrm{~km}$, green $12 \mathrm{~km}$, blue $4 \mathrm{~km}$ ), calculated using the concentration-response function developed by Laden et al. (2006).

estimated using a $4 \mathrm{~km}$ resolution). The final result is that total $\mathrm{PM}_{2.5}$ (the combined concentrations of primary and secondary $\mathrm{PM}_{2.5}$ species each with different responses to resolution) is less sensitive to model resolution on average when compared to ozone in a policy context. This result is expected to be robust to the scale and suite of policies and pollution levels studied here, but may not apply in all global or future contexts. Furthermore, as epidemiological data improve, and studies are able to provide concentration-response functions specific to individual PM species, model resolution will become a more important consideration when evaluating the human health impacts of policy impacting PM.

The results shown here are presented in the context of policy and regulation. Human health impacts estimated using multiple resolutions, but with a single concentrationresponse function, are not independent, and therefore statistical differences between them cannot be tested. In the context of policy, however, where decisions will be made based on the results estimated using a single model resolution, the findings here are important in demonstrating the tradeoffs when modeling at a coarser resolution, and in demonstrating the input characteristics where these trade-offs are most important. These results also show that the choice of concentration-response function can have a larger impact on the health benefits estimated than the choice of resolution.
Population-weighted concentrations represent a rough but commonly used estimate of the potential for human exposure. Exposure depends not only on the ambient concentration of pollutants at any given time and location, but also on the exposure patterns, intake fractions, risk factors and sensitivity of the exposed population (US EPA, 2010). As exposure mapping procedures improve, the question of appropriate model resolution will need to be revisited.

\section{Conclusions and implications for benefit analysis and policy}

We compared the difference in the population-weighted ozone concentrations between resolutions and between the 2005 base case and the 2014 control scenario. The coarsescale resolution $(36 \mathrm{~km})$ showed the largest decrease in pollution exposure from the base case to the control scenario case. This indicates the potential for coarse-scale modeling results to overestimate the benefits due to reductions in ozone in particular local or regional settings. The impact of resolution on estimated changes in $\mathrm{PM}_{2.5}$ was smaller.

We used BenMAP to calculate mortality from acute and chronic exposure to air pollution including eight peerreviewed concentration-response functions for ozone, and three for $\mathrm{PM}_{2.5}$. The mean value calculated by the coarse 


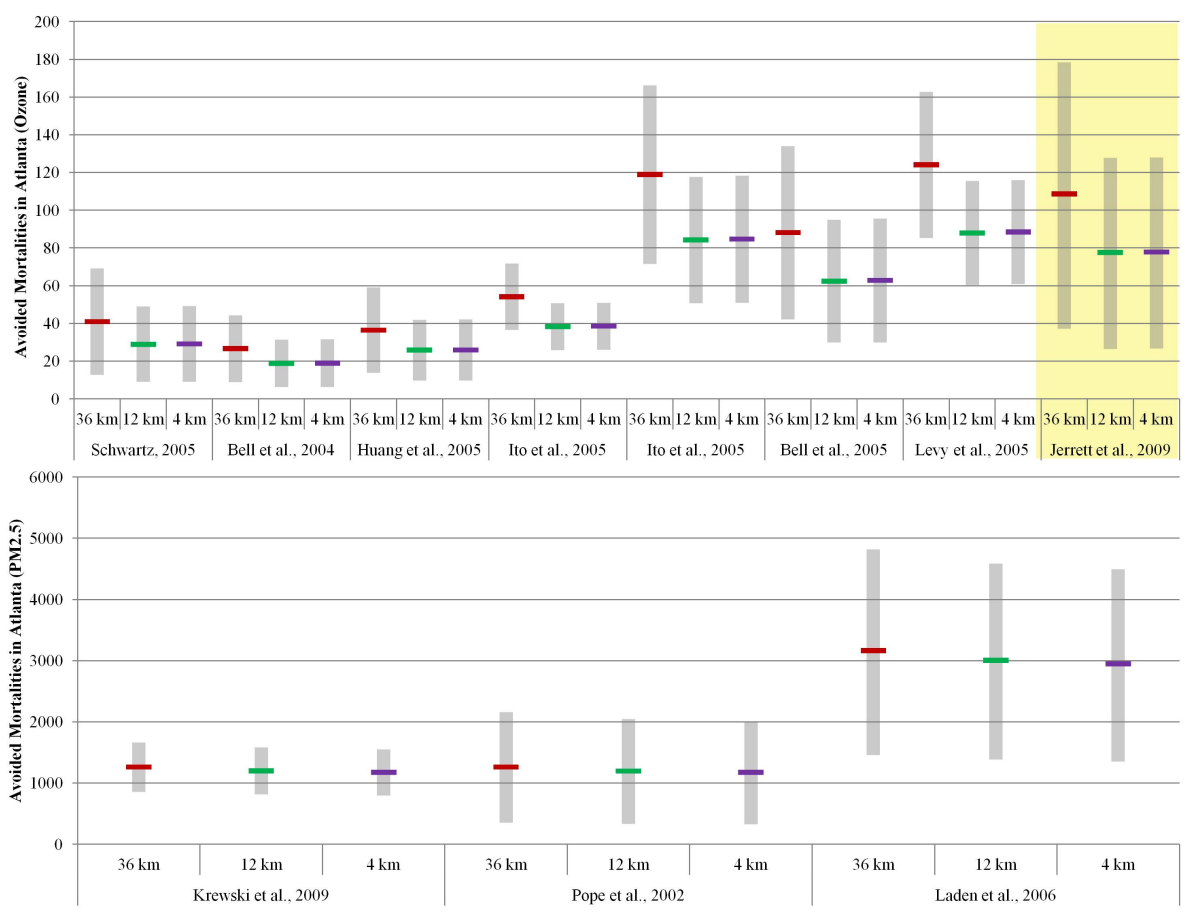

Fig. 3. (a) Mortalities avoided due to changes in ozone concentrations between the 2005 base case and the 2014 control case for each model resolution (red indicates $36 \mathrm{~km}$, green $12 \mathrm{~km}$, blue $4 \mathrm{~km}$ ), calculated using eight different concentration-response functions. The rightmost $\mathrm{CRF}$ result, highlighted in yellow, represents estimates for long-term effects of ozone exposure. All other ozone CRF results represent shortterm effects. (b) Mortalities avoided due to changes in $\mathrm{PM}_{2.5}$ concentrations between the 2005 base case and the 2014 control case for each model resolution (red indicates $36 \mathrm{~km}$, green $12 \mathrm{~km}$, blue $4 \mathrm{~km}$ ), calculated using three different concentration-response functions (CRFs). All $\mathrm{PM}_{2.5}$ CRFs represent estimates for long-term effects of $\mathrm{PM}_{2.5}$ exposure.

resolution model fell within the range of uncertainty as calculated by both the $12 \mathrm{~km}$ and the $4 \mathrm{~km}$ resolution for all $\mathrm{PM}_{2.5}$ health impacts. Since total impacts (ozone plus $\mathrm{PM}_{2.5}$ ) are dominated by $\mathrm{PM}_{2.5}$, the same claim can be made for total impacts. However, when considering just the impacts of changes in ozone on human health, resolution does matter. For all eight CRFs in Houston, New York City and Detroit, the $36 \mathrm{~km}$ mean results fell outside the uncertainty range estimated using $12 \mathrm{~km}$ and $4 \mathrm{~km}$ results. In Atlanta and Washington DC, three and five of the CRFs respectively provided $36 \mathrm{~km}$ mean results that fell outside of the finer resolution $95 \%$ uncertainty range. Therefore, we conclude that, with respect to ozone modeling in cities, the $36 \mathrm{~km}$ results have the potential to overestimate the benefits to human health when compared to the results obtained using fine-scale modeling.

Given the uncertainty associated with human health impacts and the results reported in Figs. 2 and 3, we conclude that human health benefits associated with decreases in ozone and $\mathrm{PM}_{2.5}$ (added together), when calculated at $36 \mathrm{~km}$ resolution, agree (within errors) with the benefits calculated using fine (12 km or finer) resolution modeling when using the current methodology for assessing policy decisions. However, as human health responses become better known and the span of the uncertainty range decreases, more accurate air quality modeling results will be needed, potentially requiring the use of finer scale modeling.

\section{Supplementary material related to this article is available online at http://www.atmos-chem-phys.net/14/ 969/2014/acp-14-969-2014-supplement.pdf.}

Acknowledgements. The research described has been supported by the US Environmental Protection Agency's STAR program through grant R834279, the MIT Energy Initiative Total Energy Fellowship program, the US Department of Energy Office of Science under grant DE-FG02-94ER61937 and by the MIT Joint Program on the Science and Policy of Global Change. It has not been subjected to any US EPA review and therefore does not necessarily reflect the views of the agency, and no official endorsement should be inferred. The authors would also like to thank Alison Eyth (US EPA) for assistance with the modeling episode.

Edited by: J. West 


\section{References}

Abt Associates Inc: BenMAP, Environmental Benefits Mapping and Analysis Program, User's Manual, Prepared for the US EPA Office of Air Quality Planning and Standards, available at: http://www.epa.gov/airquality/benmap/docs.html (last access: July 2012), August 2010.

Arunachalam, S., Holland, A., Do, B., and Abraczinskas, M.: A quantitative assessment of the influence of grid resolution on predictions of future-year air quality in North Carolina, USA, Atmos. Environ., 40, 5010-5026, doi:10.1016/j.atmosenv.2006.01.024, 2006.

Arunachalam, S., Wang, B., Davis, N., Baek, B. H. and Levy, J. I.: Effect of chemistry-transport model scale and resolution on population exposure to $\mathrm{PM}_{2.5}$ from aircraft emissions during landing and takeoff, Atmos. Environ., 45, 3294-3300, doi:10.1016/j.atmosenv.2011.03.029, 2011.

Bell, M. L., McDermott, A., Zeger, S. L., Sarnet, J. M., and Dominici, F.: Ozone and short-term mortality in 95 us urban communities, 1987-2000, JAMA-J. Am. Med. Assoc., 292, 23722378, doi:10.1001/jama.292.19.2372, 2004.

Bell, M. L., Dominici, F., and Samet, J. M.: A MetaAnalysis of Time-Series Studies of Ozone and Mortality With Comparison to the National Morbidity, Mortality, and Air Pollution Study, Epidemiology, 16, 436-445, doi:10.1097/01.ede.0000165817.40152.85, 2005.

CDC: "Morbidity and Mortality Weekly Report", Center for Disease Control and Prevention, available at: http://wonder.cdc.gov/ mmwr/mmwr_reps.asp (last access: March 2011), 2006.

CMAS: SMOKE v2.7 User's Manual, Institute for the Environment, The University of North Carolina at Chapel Hill, available at: http://www.smoke-model.org/version2.7/html/ (last access: February 2011), 2010.

De Meij, A., Wagner, S., Cuvelier, C., Dentener, F., Gobron, N., Thunis, P., and Schaap, M.: Model evaluation and scale issues in chemical and optical aerosol properties over the greater Milan area (Italy), for June 2001, Atmos. Res., 85, 243-267, doi:10.1016/j.atmosres.2007.02.001, 2007.

Fountoukis, C., Koraj, D., Denier van der Gon, H. A. C., Charalampidis, P. E., Pilinis, C., and Pandis, S. N.: Impact of grid resolution on the predicted fine $\mathrm{PM}$ by a regional 3D chemical transport model, Atmos. Environ., 68, 24-32, doi:10.1016/j.atmosenv.2012.11.008, 2013.

GeoLytics Inc.: Census 2015 Projection Methods, available at: http://geolytics.com/USCensus, Estimates-Projections, Data, Methodology,Products.asp (last access: November 2012), 2010.

Grell, G., Dudhia, J., and Stauffer, D. R.: A description of the fifth generation Penn State/NCAR mesoscale model (MM5), Tech. Note NCAR/TN-398+STR, National Center for Atmospheric Research, Boulder, CO, 1994.

Huang, Y., Dominici, F., and Bell, M. L.: Bayesian hierarchical distributed lag models for summer ozone exposure and cardio-respiratory mortality, Environmetrics, 16, 547-562, doi:10.1002/env.721, 2005.

Hubbell, B. J., Fann, N., and Levy, J. I.: Methodological considerations in developing local-scale health impact assessments: balancing national, regional, and local data, Air Qual. Atmos. Health, 2, 99-110, doi:10.1007/s11869-009-0037-z, 2009.
Ito, K., De Leon, S. F., and Lippmann, M.: Associations Between Ozone and Daily Mortality, Epidemiology, 16, 446-457, doi:10.1097/01.ede.0000165821.90114.7f, 2005.

Jang, J.-C. C., Jeffries, H. E., and Tonnesen, S.: Sensitivity of ozone to model grid resolution - II. Detailed process analysis for ozone chemistry, Atmos. Environ., 29, 3101-3114, doi:10.1016/13522310(95)00119-J, 1995.

Jerrett, M., Burnett, R. T., Pope, C. A., Ito, K., Thurston, G., Krewski, D., Shi, Y., Calle, E., and Thun, M.: Long-Term Ozone Exposure and Mortality, New Engl. J. Med., 360, 1085-1095, doi:10.1056/NEJMoa0803894, 2009.=

Krewski, D., Jerrett, M., Burnett, R. T., Ma, R., Hughes, E., Shi, Y., Turner, M. C., Pope III, C. A., Thurston, G., Calle, E. E., Thun, M. J., Beckerman, B., DeLuca, P., Finkelstein, N., Ito, K., Moore, D. K., Newbold, K. B., Ramsay, T., Ross, Z., Shin, H., and Tempalski, B.: Extended follow-up and spatial analysis of the American Cancer Society study linking particulate air pollution and mortality, Res. Rep. Health Eff. Inst., 140, 5-114, discussion 115-136, 2009.

Laden, F., Schwartz, J., Speizer, F. E., and Dockery, D. W.: Reduction in Fine Particulate Air Pollution and Mortality: Extended Follow-up of the Harvard Six Cities Study, Am. J. Resp. Crit. Care, 173, 667-672, doi:10.1164/rccm.200503-443OC, 2006.

Levy, J. I., Chemerynski, S. M., and Sarnat, J. A.: Ozone Exposure and Mortality, Epidemiology, 16, 458-468, doi:10.1097/01.ede.0000165820.08301.b3, 2005.

Liu, X.-H., Zhang, Y., Olsen, K. M., Wang, W.-X., Do, B. A., and Bridgers, G. M.: Responses of future air quality to emission controls over North Carolina, Part I: Model evaluation for current-year simulations, Atmos. Environ., 44, 2443-2456, doi:10.1016/j.atmosenv.2010.04.002, 2010.

Mensink, C., De Ridder, K., Deutsch, F., Lefebre, F., and Van de Vel, K.: Examples of scale interactions in local, urban, and regional air quality modelling, Atmos. Res., 89, 351-357, doi:10.1016/j.atmosres.2008.03.020, 2008.

NRC (National Research Council): Estimating the Public Health Benefits of Proposed Air Pollution Regulations, National Academies Press, Washington D.C., 2002.

Ott, D. K., Kumar, N., and Peters, T. M.: Passive sampling to capture spatial variability in $\mathrm{PM}_{10-2.5}$, Atmos. Environ., 42, 746-756, doi:10.1016/j.atmosenv.2007.09.058, 2008.

Pope III, C. A., Burnett, R. T., Thun, M. J., Calle, E. E., Krewski, D., Ito, K., and Thurston, G. D.: Lung cancer, cardiopulmonary mortality, and long-term exposure to fine particulate air pollution, JAMA-J. Am. Med. Assoc., 287, 1132-1141, 2002.

Punger, E. M. and West, J. J.: The effect of grid resolution on estimates of the burden of ozone and fine particulate matter on premature mortality in the USA, Air Qual. Atmos. Health, 6, 563573, doi:10.1007/s11869-013-0197-8, 2013.

Queen, A. and Zhang, Y.: Examining the sensitivity of MM5CMAQ predictions to explicit microphysics schemes and horizontal grid resolutions, Part III - The impact of horizontal grid resolution, Atmos. Environ., 42, 3869-3881, doi:10.1016/j.atmosenv.2008.02.035, 2008.

Schwartz, J.: How sensitive is the association between ozone and daily deaths to control for temperature?, Am. J. Respir. Crit. Care Med., 171, 627-631, doi:10.1164/rccm.200407-933OC, 2005.

Shrestha, K. L., Kondo, A., Kaga, A., and Inoue, Y.: Highresolution modeling and evaluation of ozone air quality of 
Osaka using MM5-CMAQ system, J. Environ. Sci., 21, 782-789, doi:10.1016/S1001-0742(08)62341-4, 2009.

TCEQ: Protocol for Eight-Hour Ozone Modeling of the Houston/Galveston/Brazoria Area, Air Quality Division, Texas Commission on Environmental Quality, available at: http://www.tceq.texas.gov/assets/public/implementation/air/am/ modeling/hgb8h2/doc/HGB8H2_Protocol_20090715.pdf (last access: July 2009), 2009.

Thompson, T. M. and Selin, N. E.: Influence of air quality model resolution on uncertainty associated with health impacts, Atmos. Chem. Phys., 12, 9753-9762, doi:10.5194/acp-12-97532012, 2012.

Tie, X., Brasseur, G., and Ying, Z.: Impact of model resolution on chemical ozone formation in Mexico City: application of the WRF-Chem model, Atmos. Chem. Phys., 10, 8983-8995, doi:10.5194/acp-10-8983-2010, 2010.

US EPA: Guidance on the Use of Models and Other Analyses for Demonstrating Attainment of Air Quality Goals for Ozone, $\mathrm{PM}_{2.5}$, and Regional Haze, Office of Air Quality Planning and Standards, Report B-07-002, available at: http://www.epa.gov/ scram001/guidance/guide/final-03-pm-rh-guidance.pdf (last access: April 2011), 2007.

US EPA: Stochastic Human Exposure and Dose Simulation (SHEDS) Multimedia Model Version 3, Office of Research and Development: Human Exposure and Atmospheric Sciences, available at: http://www.epa.gov/heasd/products/sheds_ multimedia/sheds_mm.html (last access: March 2011), 2010.

US EPA: The Benefits and Costs of the Clean Air Act from 1990 to 2020, Office of Air and Radiation, Second Prospective Study, available at: http://www.epa.gov/oar/sect812/prospective2.html (last access: February 2013), 2011 a.
US EPA, Air Quality Modeling Final Rule Technical Support Document, Office of Air Quality Planning and Standards, available at: http://www.epa.gov/airtransport/pdfs/AQModeling.pdf (last access: March 2013), 2011b.

US EPA, Emissions Inventory Final Rule Technical Support Document, Office of Air and Radiation, available at: http:// www.epa.gov/airtransport/pdfs/EmissionsInventory.pdf (last access: March 2013), 2011c.

US EPA: Regulatory Impact Analysis for the Federal Implementation Plans to Reduce Interstate Transport of Fine Particulate Matter and Ozone in 27 States, Office of Air and Radiation, available at: http://www.epa.gov/airtransport/pdfs/FinalRIA.pdf (last access: December 2012), 2011d.

US EPA: Integrated Science Assessment for Ozone and Related Photochemical Oxidants, Office of Research and Development, available at: http://yosemite.epa.gov/sab/ sabproduct.nsf/264cb1227d55e02c85257402007446a4/ F1FF5278C8BCEFA48525776D006DB48B/\$File/Ozone_ ISA_ERD1.pdf (last access: May 2011), 2011e.

US EPA: Regulatory Impact Analysis for the Final Revisions to the National Ambient Air Quality Standards for Particulate Matter, Office of Air Quality Planning and Standards, available at: http://www.epa.gov/ttnecas1/regdata/RIAs/finalria.pdf (last access: August 2013), 2012.

Zhang, Y., Liu, X.-H., Olsen, K. M., Wang, W.-X., Do, B. A., and Bridgers, G. M.: Responses of future air quality to emission controls over North Carolina, Part II: Analyses of future-year predictions and their policy implications, Atmos. Environ., 44, 27672779, doi:10.1016/j.atmosenv.2010.03.022, 2010. 